\title{
PESQUISAS SOBRE PERCEPÇÃO AMBIENTAL EM COMUNIDADES TRADICIONAIS COM ABORDAGENS SOBRE OS MOTIVOS DA VALORAÇÃO AMBIENTAL: UMA INCURSÃO NAS DISSERTAÇÕES E TESES DE 2009 - 2017
}

Joscélia Monteiro Santos de Brito
Instituto Federal da Bahia (IFBA) e Universidade Federal do Sul da Bahia (UFSB), Porto Seguro, BA, Brasil
Programa de Pós-Graduação em Ciências e Tecnologias Ambientais (PPGCTA)

josceliabrito@ifba.edu.br

Emilly da Silva Farias

Universidade Estadual de Santa Cruz (UESC), Ilhéus, BA, Brasil Programa de Pós-Graduação em Desenvolvimento e Meio Ambiente (PRODEMA) emillyfarias10@hotmail.com

Raquel Viana Quinelato Universidade Estadual de Santa Cruz (UESC), Ilhéus, BA, Brasil Programa de Pós-Graduação em Desenvolvimento e Meio Ambiente (PRODEMA) raquelsviana@hotmail.com

Allison Gonçalves Silva Instituto Federal da Bahia (IFBA) e Universidade Federal do Sul da Bahia (UFSB), Porto Seguro, BA, Brasil Programa de Pós-Graduação em Ciências e Tecnologias Ambientais (PPGCTA) allisongonçalves@ifba.edu.br

\begin{abstract}
RESUMO
Pesquisas sobre percepção ambiental têm potencial para compreender o modo e os motivos como os indivíduos valoram os recursos naturais e o meio em que vivem. Assim, considerando o elo existente entre os povos de comunidades tradicionais e o ambiente que os rodeia, esse artigo se propõe a resumir algumas discussões presentes em teses e dissertações entre os anos de 2009 - 2017 disponíveis na plataforma do Instituto Brasileiro de Informação em Ciência e Tecnologia (lbict), com abordagem subjacente ou não sobre os motivos da valoração ambiental. Para tanto, foi utilizada a Revisão Integrativa (RI) seguindo as seguintes etapas: I) Definição da questão; II) Investigação na literatura; III) Definição das informações a serem extraídas dos estudos; IV) Avaliação dos estudos incluídos na revisão; V) Interpretação dos dados; e, VI) Síntese dos conteúdos. Os resultados e discussão foram apresentados em três categorias: I) Valoração simbólica, que está relacionada às questões culturais, religiosas, emocionais, ecológicas, morais e estéticas; II) Valoração econômica, que se relaciona ao valor de mercado e comercialização e; III) Territorialidade e gestão ambiental participativa. Os resultados sugerem que estudos sobre percepção ambiental abordam valoração ambiental de forma direta ou indireta e pode ser importante instrumento para gestão ambiental participativa.
\end{abstract}

Palavras-chave: Comunidades tradicionais. Gestão ambiental participativa. Percepção ambiental. Valoração simbólica e econômica.

\section{RESEARCH ON ENVIRONMENTAL PERCEPTION IN TRADITIONAL COMMUNITIES WITH APPROACHES ON ENVIRONMENTAL ASSESSMENT REASONS: A RAID IN DISSERTATIONS AND THESES FOR 2009 - 2017}

\begin{abstract}
Research on environmental perception has the potential to understand how and why individuals value natural resources and the environment in which they live. Thus, considering the link between the peoples of traditional communities and the environment that surrounds them, this article proposes to summarize some discussions present in theses and dissertations between the years 2009 - 2017 available on the platform of the Brazilian
\end{abstract}

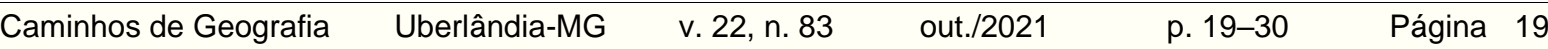


Pesquisas sobre percepção ambiental em comunidades tradicionais com abordagens sobre os motivos da valoração ambiental: uma incursão nas dissertações e teses de 2009 - 2017
Joscélia Monteiro Santos de Brito Emilly da Silva Farias Raquel Viana Quinelato Allison Gonçalves Silva

Institute of Information in Science and Technology (Ibict), with an underlying approach or not on the reasons for environmental valuation. For this purpose, the Integrative Review (IR) was used, following the steps below: I) Definition of the question; II) Literature research; III) Definition of the information to be extracted from the studies; IV) Evaluation of the studies included in the review; V) Interpretation of data; and, VI) Content synthesis. The results and discussion were presented in three categories: I) Symbolic valuation, that is related to cultural, religious, emotional, ecological, moral and aesthetic issues; II) Economic valuation, that is related to market and commercialization value and; III) Territoriality and participatory environmental management. The results suggest that studies on environmental perception address environmental valuation directly or indirectly and can be an important instrument for participatory environmental management.

Keywords: Traditional communities. Participatory environmental management. Environmental perception. Symbolic and economic valuation.

\section{INTRODUÇÃO}

Estudos sobre percepção ambiental são indicados para conhecer a relação da população com o meio em que vive e, têm potencial para apontar caminhos mais apropriados para a gestão ambiental, através da reflexão sobre o uso dos recursos naturais, podendo seus resultados estimular a concretização de ações integradas e participativas para superação de problemas ambientais (SORRENTINO et al., 2005; BARBIERI e SILVA, 2011; MENDONÇA e COLESENTI, 2015). Esse método é relevante ao auxiliar na investigação dos conhecimentos, valores, opiniões, atitudes e expectativas que as pessoas têm em relação ao seu local de moradia, além de propiciar meios de sensibilização e conscientização quanto ao uso racional dos recursos naturais (UNESCO, 1973; JACOBI, 2005; SUESS; BEZERRA; SOBRINHO, 2013).

Considerando que a forma como os indivíduos percebem o seu meio depende de fatores socioambientais e cognitivos, pesquisas voltadas para a percepção ambiental contribui com a construção de uma visão profunda e fidedigna sobre a população pesquisada. Assim pode ser uma ferramenta para promover o estreitamento das relações entre sociedade e poder público, através de intervenções de gestão e/ou educação ambiental condizentes com cada realidade (ROSA e ARNOLDI, 2008; BARBIERI e SILVA, 2011). Além disso, por meio da percepção ambiental torna-se possível detectar os motivos da valoração ambiental de determinado lugar a partir da relação de pertencimento das pessoas com o seu meio (RAYEL, 2016).

Deste modo, no contexto da percepção ambiental, o conceito de topofilia é fundamental por trazer contribuições sobre como o meio ambiente é percebido e vivido pelos indivíduos, com respeito aos seus valores e tradições culturais. A topofilia busca a compreensão do significado que é atribuído pelo indivíduo para o mundo em que habita, ou seja, quais valores são conferidos por ele para o ambiente em que se encontra. Desta forma, a valoração ambiental pode ser descrita como algo proveniente do elo afetivo entre a pessoa e o lugar ou ambiente físico, vivido e concreto, focando no parâmetro sentimental ou subjetivo para definição do valor ecossistêmico, não levando em consideração somente os parâmetros financeiros e econômicos (TUAN, 2015).

Nos últimos tempos, o foco do utilitarismo ambiental está cada vez mais atrelado a valorização financeira, devido ao uso de determinado recurso de forma exagerada voltado para fins econômicos (CALILÉ, 2001; TUAN, 2015), fazendo com que as visões e valores simbólicos do meio natural se percam de forma irreparável, e à medida que se dispersam o mesmo ocorre com o processo de racionalização dos modos da vida (PIERUCCI, 2003). Dito isso, vale destacar que a valoração ambiental também está ligada aos serviços públicos universais que a natureza realiza gratuitamente ao ser humano, aos aspectos morais, ao reconhecer o direito de existir de todas as espécies, ao valor estético, recreacional, teológico, espiritual, para inspiração artística e muitos outros que podem ser conhecidos a partir da visão do indivíduo em sua realidade específica (RICKLEFS e RELYEA, 2010).

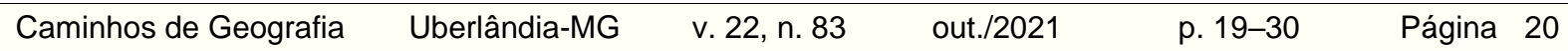


Pesquisas sobre percepção ambiental em comunidades tradicionais com abordagens sobre os motivos da valoração ambiental: uma incursão nas dissertações e teses de 2009 - 2017
Joscélia Monteiro Santos de Brito Emilly da Silva Farias Raquel Viana Quinelato Allison Gonçalves Silva

De acordo com Cisotto (2013, p.01), a proposta de estudos sob a luz da topofilia, induz a uma reflexão sobre "quais foram e quais são nossos ideais ambientais, como o percebemos, nos situamos, significamos o mundo que ocupamos, se propondo a examinar a percepção e os valores ambientais". Assim, estudos que buscam compreender a relação pessoa-ambiente a partir da topofilia, costumam explicitar a construção dos valores relacionados ao meio ambiente, as mudanças de visão de mundo e a compreensão de diversas experiências ambientais e, portanto, seus diferentes valores.

Diante do exposto, a presente revisão tem o objetivo de sistematizar as produções científicas de teses e dissertações entre os anos de 2009 e 2017 voltadas para estudos sobre percepção ambiental em comunidades tradicionais com abordagem subjacente ou não sobre os motivos da valoração ambiental, sejam elas simbólicas ou econômicas. Portanto, não se pretende focar nos métodos de mensuração econômica dos recursos ambientais e sim nos motivos que levam a valoração, fruto do elo da relação pessoa-natureza. A partir dessa revisão é possível vislumbrar a multiplicidade de aspectos de valoração ambiental simbólica e econômica com base em estudos sobre percepção ambiental em comunidades tradicionais. Tal conhecimento instiga a necessidade de empreender esforços para conhecer a visão e relação desses povos com os recursos naturais disponíveis, a partir da relação dessas populações com os seus territórios. Esse conhecimento, por sua vez, pode subsidiar políticas e ações de gestão ambiental mais participativas e condizentes com a realidade local.

\section{METODOLOGIA}

A investigação que se apresenta utiliza como método a Revisão Integrativa (RI) e segue as seguintes etapas: I) Definição da questão a ser pesquisada; II) Investigação na literatura; III) Definição das informações a serem extraídas dos estudos selecionados; IV) Avaliação dos estudos incluídos na revisão; V) Interpretação dos dados coletados; e por último, VI) Síntese dos conteúdos (MENDES; SILVEIRA; GALVÃO, 2008).

Primeiro estabeleceu-se o tema a ser estudado, que por sua vez, delineou os objetivos e os descritores a serem utilizados. Sendo a definição do problema: Quais os motivos da valoração ambiental em comunidades tradicionais? A partir dessa definição, foram estabelecidos os seguintes descritores: "percepção ambiental em comunidades tradicionais" + "valoração dos recursos naturais" e "comunidades tradicionais e valoração ambiental".

As buscas foram feitas considerando os anos de 2009 a 2019 e, foram incluídas as pesquisas que estivessem disponíveis na integra na Biblioteca Digital Brasileira de Teses e Dissertações (BDTD), da plataforma do Instituto Brasileiro de Informação em Ciência e Tecnologia (Ibict). Para exclusão adotou-se os seguintes critérios: I) pesquisas que não foram realizadas em comunidades tradicionais II) pesquisas que mesmo tendo sido realizadas em comunidades tradicionais não tivessem foco direto ou indireto na percepção ambiental e, III) pesquisas em comunidades tradicionais que não trouxessem ao longo da discussão, informações acerca dos aspectos simbólicos ou econômicos da valoração ambiental. A partir da leitura do resumo e/ou introdução, foram aplicados os critérios I e II e na leitura completa do material aplicou-se os critérios II e III.

Posteriormente, foi realizada a categorização dos dados encontrados entre aspectos de valoração simbólica e valoração econômica e ainda, publicações com enfoques principais ou subjacentes sobre a temática. Em seguida foi realizada a interpretação e resumo dos dados obtidos.

\section{RESULTADOS E DISCUSSÃO}

Foram encontrados 37 trabalhos acadêmicos entre teses e dissertações com linha de pesquisa

$\begin{array}{llllll}\text { Caminhos de Geografia } & \text { Uberlândia-MG } & \text { v. 22, n. } 83 & \text { out./2021 } & \text { p. 19-30 } & \text { Página } 21\end{array}$


Pesquisas sobre percepção ambiental em comunidades tradicionais com abordagens sobre os motivos da valoração ambiental: uma incursão nas dissertações e teses de 2009 - 2017
Joscélia Monteiro Santos de Brito Emilly da Silva Farias Raquel Viana Quinelato Allison Gonçalves Silva

relacionada ao tema investigado. Após a leitura dos resumos e/ou introdução, foram selecionados 19 trabalhos, que por sua vez, foram lidos por completo para uma seleção refinada considerando os critérios de exclusão, conforme metodologia apresentada. Por fim, foram obtidas 13 pesquisas científicas, sendo 05 teses e 08 dissertações, conforme Tabela 1.

Tabela 1 - Informações das teses e dissertações obtidas e organizadas pelas autoras.

\begin{tabular}{|c|c|c|c|c|}
\hline Título & $\begin{array}{l}\text { Tipo de } \\
\text { pesquisa }\end{array}$ & Autor(a) & Ano & Objetivo(s) \\
\hline $\begin{array}{c}\text { Percepção ambiental: as } \\
\text { transformações no cotidiano } \\
\text { de caiçaras de Ubatuba-SP } \\
\text { na década de } 1960 \text { e na } \\
\text { primeira década do século } \\
\text { XXI }\end{array}$ & Dissertação & Joice Fernandes & 2009 & $\begin{array}{l}\text { Analisar a sustentabilidade } \\
\text { através de comunidade } \\
\text { tradicional com abordagem do } \\
\text { assunto sob a linha de } \\
\text { pesquisa conhecida como } \\
\text { Ecologia Cultural, com } \\
\text { colaborações conteudistas das } \\
\text { vertentes neo-marxista e } \\
\text { escola-novista, através da } \\
\text { técnica da História Oral. }\end{array}$ \\
\hline $\begin{array}{l}\text { Lugar, recursos e saberes } \\
\text { dos ribeirinhos do médio rio } \\
\text { Cuiabá, Mato Grosso }\end{array}$ & Tese & $\begin{array}{c}\text { Maria Saleti Ferraz } \\
\text { Dias Ferreira }\end{array}$ & 2010 & $\begin{array}{c}\text { Conhecer as formas de } \\
\text { manejo, as práticas de usos } \\
\text { dos serviços do ecossistema, } \\
\text { as representações sobre o } \\
\text { lugar de vivência e sobre a } \\
\text { biodiversidade, para conhecer } \\
\text { as comunidades ribeirinhas, as } \\
\text { relações que estabelecem com } \\
\text { os serviços do ecossistema, a } \\
\text { percepção e os saberes que } \\
\text { constroem sobre o espaço } \\
\text { onde desenvolvem suas } \\
\text { vivências e desenvolver ações } \\
\text { de educação ambiental na } \\
\text { escola para mediar a } \\
\text { aproximação da prática } \\
\text { pedagógica e a prática } \\
\text { vivenciada. }\end{array}$ \\
\hline
\end{tabular}

Entendendo as interações entre povos pesqueiros, manguezal e Área protegida: RDS estadual

Ponta do Tubarão (RN, BRASIL)
Registrar o valor biológico, ecológico e social dos manguezais na percepção dos pescadores, marisqueiras e catadores de caranguejo, bem como avaliar a influência da reserva na conservação do manguezal e qualidade de vida da população.
O conhecimento ecológico local e a percepção ambiental de uma população de pescadores do Rio Grande do Sul
Dissertação Patrícia Pereira Mattos

2011
Descrever o saber ambiental e analisar a noção conservacionista de uma destas populações tradicionais, aqui representadas por pescadores artesanais. 
Pesquisas sobre percepção ambiental em comunidades tradicionais com abordagens sobre os motivos da valoração ambiental: uma incursão nas dissertações e teses de 2009 - 2017
Joscélia Monteiro Santos de Brito Emilly da Silva Farias Raquel Viana Quinelato Allison Gonçalves Silva

\section{Pagamentos pelos serviços ambientais no ecossistema manguezal das unidades de conservação de \\ Sabiaguaba: Modelo de contrato e outras medidas de conservação.}

Marco Andrés González Caranton

Dissertação
Promover a estruturação teórica de um modelo de contrato em pagamentos pelos serviços ambientais (PSA), baixo uma perspectiva de gestão pública, e como parte Integrada da metodologia fator verde (fv), a ser implementada no manguezal das Unidades de conservação de Sabiaguaba.

Analisar grupos sociais do
município de Cananéia, Litora

Representações e percepções sobre ambiente e conservação como subsídio ao Gerenciamento Costeiro Integrado: estudo de caso com grupos sociais da região de Cananéia, litoral sul do Estado de São Paulo Sul do Estado de São Paulo, quanto às suas percepções sobre o ambiente da região, considerando possíveis mudanças ambientais, responsabilidades e, ao mesmo tempo, as representações sociais de meio ambiente e Unidades de Conservação.
Comunidades Sustentáveis: um estudo de percepção, interpretação e valoração da paisagem mediante 0 conhecimento tradicional
Davi Gutierrez Antonio

2013
Paulo Sérgio Silvino do Nascimento

Compreender as dinâmicas comunitárias pela análise do quilombo Pedro Cubas

(Eldorado/SP), e de que forma ocorre a valoração da paisagem mediante 0 conhecimento tradicional, possibilitando a busca pelo desenvolvimento territorial sustentável da comunidade.

Propor uma metodologia de identificação e análise dos

Gestão em áreas protegidas: proposição metodológica para análise de impactos

socioambientais nas comunidades tradicionais da APA Chapada do Araripe

\section{Tese}

2013 impactos da gestão da Área de

Proteção Ambiental nas comunidades tradicionais rurais, tendo a APA Chapada do Araripe e as suas comunidades tradicionais rurais como sujeitos desta pesquisa.
Economia do conhecimento tradicional e a valoração econômica como instrumento de sua Conservação: o caso das mandiocas açucaradas
Felipe Stock Vieira

2014

\section{Dissertação}

Analisar a relevância dos métodos de valoração econômica do meio ambiente para estimar os benefícios econômicos (sociais) da conservação da diversidade biológica por comunidades tradicionais.
Etnobotânica e percepção ambiental de Pescadores e coletoras tradicionais submetidos à escassez de recursos vegetais silvestres
André Luiz Bezerra Falcão Freire

2015
Classificar, compreender, interpretar o mundo através de comunidade tradicional com base em "etnoconhecimento" como: (I) saber, saber-fazer e meios de aprender (II) transmitidos oral e dependentemente do contexto (III) que façam referência ou dêem sentido ao mundo (IV) e conjuguem memória e viver cotidiano. Por extensão, quando o etnoconhecimento se refere às plantas, falamos de conhecimento etnobotânico. 
Pesquisas sobre percepção ambiental em comunidades tradicionais com abordagens sobre os motivos da valoração ambiental: uma incursão nas dissertações e teses de 2009 - 2017
Joscélia Monteiro Santos de Brito Emilly da Silva Farias Raquel Viana Quinelato Allison Gonçalves Silva

\begin{tabular}{|c|c|c|c|c|}
\hline $\begin{array}{c}\text { Estrutura florística e } \\
\text { implicações socioambientais } \\
\text { na área de preservação } \\
\text { permanente Tarumã Mirim, } \\
\text { MANAUS - AM }\end{array}$ & Dissertação & Renata Lima Pimentel & 2016 & $\begin{array}{c}\text { Analisar a característica } \\
\text { fitossociológica e } \\
\text { socioambiental da área de } \\
\text { preservação permanente } \\
\text { Tarumã Mirim, Manaus - AM. }\end{array}$ \\
\hline $\begin{array}{l}\text { Serviços ecossistêmicos e } \\
\text { interações com uma } \\
\text { comunidade } \\
\text { afrodescendente no pacífico } \\
\text { colombiano: dos riscos à } \\
\text { proteção da biodiversidade }\end{array}$ & Dissertação & Laura Lozada Ordonez & 2017 & $\begin{array}{l}\text { Analisar a percepção em } \\
\text { relação aos serviços } \\
\text { ecossistêmicos (SË) da } \\
\text { comunidade de Joví (povoado } \\
\text { afrodescendente do Pacífico } \\
\text { Colobiano) e de seus } \\
\text { especialistas, comparando-as } \\
\text { com as percepções dos } \\
\text { especialistas técnicos de } \\
\text { diferentes disciplinas, com a } \\
\text { finalidade de identificar, nesse } \\
\text { exercício, práticas locais } \\
\text { protetores ou de risco para a } \\
\text { biodiversidade. }\end{array}$ \\
\hline
\end{tabular}

Territorialidade, saúde e meio ambiente: conexões, saberes e práticas em comunidades quilombolas de Sergipe
Analisar como os saberes e práticas tradicionais de cuidado em saúde constroem territorialidades que contribuem para conservação ambiental em comunidades quilombolas.

Fonte - Elaborada pelas autoras.

Em relação ao ano de publicação/defesa, apesar das buscas terem ocorrido considerando os anos de 2009 a 2019, os trabalhos selecionados abrangeram os anos de 2009 a 2017, todos de instituições superiores estaduais e federais do Brasil. Vale destacar que a metodologia adotada nos estudos selecionados, variaram entre a abordagem qualitativa e quantitativa, sendo que 4 pesquisas apresentaram a questão da valoração ambiental como tema principal, tendo sido as pesquisas de Mattos (2011), Caraton (2012), Antonio, (2013) e Vieira (2014). Nas demais pesquisas o tema foi abordado de forma subjacente.

Após análise das pesquisas acadêmicas encontradas e para melhor compreensão dos motivos apontados nos estudos sobre as razões para valoração ambiental, foram estabelecidas três categorias: I) Valoração simbólica e subjetiva que está relacionada às questões culturais, religiosas, emocionais, ecológicas, morais e estéticas; II) Valoração econômica que se relaciona ao valor de mercado e comercialização e; III) Territorialidade e gestão ambiental participativa.

\section{Aspectos relativos à valoração ambiental simbólica}

Embora os estudos da valoração dos recursos ambientais nos últimos tempos estejam cada vez mais voltados para o valor econômico, alguns estudos têm uma abordagem não econômica, dando maior ênfase para preferências socioculturais na perspectiva dos valores humanos, atitudes e crenças (ORDONEZ, 2017).

A partir da análise dos dados coletados, foi possível vislumbrar que aspectos sobre a valoração da paisagem em comunidades tradicionais estão relacionados ao vínculo com as terras herdadas de seus antepassados, que além do valor material, também possuem valor afetivo, assim influenciando no modo de uso dos recursos naturais disponíveis (ANTONIO, 2013; LACERDA, 2017). A posse e o elo histórico e cultural desses povos com as terras denotam o pertencimento ao local, que atribuem valores e emoções que se expressam na identidade da população, demonstrando que a construção dos valores da paisagem dessas pessoas está pautada na relação que possuem com o território, portanto dos sentimentos e da cognição, por meio das informações e conhecimentos a respeito compartilhados na própria comunidade (ANTONIO, 2013). 
Pesquisas sobre percepção ambiental em comunidades tradicionais com abordagens sobre os motivos da valoração ambiental: uma incursão nas dissertações e teses de 2009 - 2017
Joscélia Monteiro Santos de Brito Emilly da Silva Farias Raquel Viana Quinelato Allison Gonçalves Silva

Deste modo, destacam-se as razões da valoração da paisagem pelos aspectos históricos, estéticos, ecológicos, religiosos e rurais (FERNANDES, 2009). Alguns estudos revelam uma visão ambiental política da comunidade em que indivíduos se reconhecem como responsáveis por "cuidar" dos recursos que naturalmente estão disponíveis para serem explorados (ANTONIO, 2013). Estando esse ato de cuidar perpetrando muitos outros aspectos, como pode ser observado em relação ao banco de sementes crioulas, cujo ato não se remete apenas ao "cuidar", mas está vinculado inteiramente às questões ambientais, saúde, cultura e economia da comunidade (LACERDA, 2017).

Mesmo os estudos cujo objetivo centra-se na valoração econômica dos serviços ecossistêmicos proporcionados pelo ambiental natural de uma determinada comunidade, se propuseram a verificar diretamente com as populações estudadas os elementos e razões associadas à valoração ambiental da paisagem e demais elementos compositores do meio, evidenciando que não é possível pensar na gestão ambiental eficiente sem considerar o modo de organização social, política e cultural dessas pessoas em seus territórios. Caranton (2012) reconhece que as comunidades compostas por diferentes ecossistemas, normalmente possuem importantes valores culturais e tem alta qualidade estética, além dos locais sagrados que preservam valor ancestral. O mesmo autor ressalta que esses espaços possuem "valores simbólicos e culturais dos bens e serviços do ecossistema e os valores do modo de vida das comunidades" (CARANTON, 2012, p. 63).

Destaca-se, dentre os estudos selecionados, a valoração da água como elemento que, para além dos serviços ecossistêmicos e simbolismo cultural, é diretamente responsável pela qualidade de vida da população, assim como outros ambientes, tais como os manguezais, que também teve o seu valor apontado como elemento natural responsável pela qualidade de vida das comunidades (MATTOS, 2011; CARANTON, 2012). Para comunidades tradicionais, a interação entre pessoa e natureza é tão complexa, que os serviços fornecidos pelo ecossistema e os recursos naturais têm relação indissolúvel com os serviços culturais, como exemplo as florestas que são valoradas pelas comunidades pelo uso das plantas através da medicina popular, fruto da interação cultural, inclusive entre gerações (FERREIRA, 2010; FREIRE, 2015; LACERDA, 2017; ORDONEZ, 2017). Em outros casos, a valoração ocorre como uma "moeda de troca", em que o ser humano deve cuidar da natureza para que possa usufruir dos seus recursos (PIMENTEL, 2016).

A valoração dos recursos naturais foi apontada também devido a sua importância para apreciação cênica e estética, que ocorre através dos sentidos como a visão, olfato e audição (MARTINEZ, 2012; PIMENTEL, 2016). Há revelações de que os elementos da natureza provocam o sentimento de amor e carinho, além de fazer com que 0 indivíduo se sinta melhor fisicamente, mentalmente e espiritualmente (PIMENTEL, 2016; LACERDA, 2017). Além disso, a valoração ambiental se dá também quando o meio proporciona uma profissão, como no caso de pescadores e marisqueiros, que para além dos retornos econômicos, traz identidade e satisfação pessoal (MATTOS, 2011).

\section{Aspectos relativos à valoração ambiental econômica}

Considerando o ser humano como parte do meio, existem estudos sobre valoração ambiental em comunidades tradicionais que incluem a valoração das práticas dessas comunidades como forma de contribuir para conservação da biodiversidade, ou seja, a valoração do próprio ser humano com suas tradições, reconhecendo-o como parte da natureza e não como um ser superior e distante dela (VIEIRA, 2014; ORDONEZ, 2017; LACERDA, 2017). Atividades como o extrativismo, turismo e recreação permeiam motivos para valoração econômica em comunidades tradicionais que, somados aos seus valores simbólicos, culturais, religiosos, podem agregar ainda mais valor às atividades econômicas desenvolvidas, sendo a exploração econômica apontada como elemento importante para a permanência de programas de conservação nesses territórios (FERREIRA, 2010; CARANTON, 2012; BAPTISTA, 2011). De acordo com Vieira (2014), o valor do uso direto que traz benefícios econômicos e, o valor do não uso que está voltado para os serviços ambientais, culturais e da própria existência do recurso em função da comunidade que a manteve, devem ser considerados ao valorar economicamente os recursos naturais.

O incentivo à exploração econômica de atividades recreativas, tais como ecoturismo, pesca esportiva e outras atividades ao ar livre, através de uma gestão participativa, é apontada como meio para promoção e fortalecimento da educação ambiental, de modo a resgatar valores simbólicos, usos tradicionais do solo e modo de vida das comunidades, além de proporcionar uma reflexão sobre uma nova forma de uso dos recursos naturais, caso as atividades tipicamente tradicionais estejam

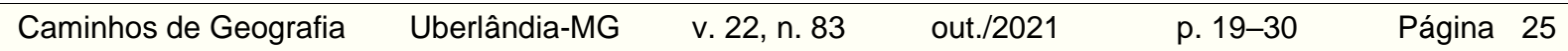


Pesquisas sobre percepção ambiental em comunidades tradicionais com abordagens sobre os motivos da valoração ambiental: uma incursão nas dissertações e teses de 2009 - 2017
Joscélia Monteiro Santos de Brito Emilly da Silva Farias Raquel Viana Quinelato Allison Gonçalves Silva

provocando algum dano ambiental (CARANTON, 2012; ANTONIO, 2017). Ordonez (2017) diz que, mudanças na dinâmica de uso e ocupação da terra para intensificação da renda e emprego em comunidades tradicionais, levaram ao declínio do valor estético da paisagem e muitas vezes ao esgotamento das águas subterrâneas e consequentemente impactam nos seus valores econômicos e qualidade de vida desses povos.

\section{Territorialidade e gestão ambiental participativa}

Comunidades indígenas, quilombolas e ribeirinhas têm utilizado e domesticado diversos elementos da diversidade biológica em diferentes pontos do planeta. Estudar como essas comunidades percebem o seu meio é uma ferramenta importante para uma gestão ambiental mais coerente, uma vez que esta perpassa normas e legislações, sendo o fator humano, elemento essencial neste processo (BAPTISTA, 2011; MARTINEZ, 2012; VIEIRA, 2014). Todavia, as percepções e os valores atribuídos aos recursos naturais em determinado território estão diretamente relacionados com os modos de vida dessas pessoas, sua organização cultural, social e política. Portanto, não seria apropriado falar em modelo padrão para investigação das percepções em comunidades tradicionais, assim também, não se pode inferir que todas elas possuem o mesmo tipo de percepção e/ou atribuem de forma igual os valores simbólicos ou econômicos aos recursos naturais disponíveis em seus territórios. Ou seja, a identidade do território não ocorre por sua simples existência, mas a partir da coletividade que nele vive por meio de um processo dinâmico, flexível e dialético, repleto de possibilidades que se realizam de forma singular no tempo e espaço (LACERDA, 2017).

Embora a pesquisa realizada por Lacerda (2017) não esteja focada diretamente na valoração ambiental, a questão da territorialidade para a análise das percepções se mostrou relevante. Para o autor, políticas ambientais em territórios de comunidades tradicionais, precisam se adequar às características e às inter-relações com o lugar vivido pois, essas relações de uso estão atreladas as necessidades pessoais e coletivas, as atitudes de valoração, respeito e cuidado que esses povos têm com o ambiente que os abriga. Considerando que eles dependem dos recursos que manterão a comunidade em níveis de funcionamento compatíveis com as suas necessidades internas. Essa mesma constatação é ocorre na pesquisa de Antonio (2013), que traz para sua análise os aspectos da territorialidade da área de estudo.

Os múltiplos territórios e as múltiplas territorialidades dos povos e comunidades tradicionais envolvem processos complexos desde a ocupação desses territórios que, passou e ainda passa recorrentemente por profundas mudanças, marcadas por histórias de lutas quanto a demarcação, usurpação e apropriação de suas terras. Por isso, estudar e compreender a percepção dos povos tradicionais para subsidiar ações práticas requer reconhecer as características destes territórios em sua pluralidade e as territorialidades específicas de cada povo e comunidade tradicional. Portanto, o modo como esses povos percebem e valoram os recursos naturais está intrinsicamente relacionado as memórias, identidades coletivas, relação de pertencimento e afetividade, além da organização política e cultural estabelecidos em cada comunidade (MONTEIRO e ALMEIDA, 2020).

Deste modo, a intensa relação desses povos com o território é central nesse tipo de investigação, pois a partir dessa relação é que se estabelecem os sistemas de representações, símbolos, mitos e referenciais espaciais, cujas expressões de valores simbólicos e econômicos se dá com base numa complexa trama de relações sociais, como também de simbiose entre a natureza, os recursos e os ciclos naturais que se constitui de modo singular em cada comunidade (DIEGUES, 2000; 2004). Além disso, há que se considerar as interferências nos modos de vida desses povos advindos das lutas territoriais, intervenções Estatais e a própria mudança do perfil econômico, muitas vezes ocorrida a partir da sociedade moderna e incorporado gradativamente por essas comunidades.

Diante do exposto, o conceito de comunidade tradicional, já não traduz completa harmonia com o meio em que vive e, de acordo com Ordonez (2017) pesquisas apontam que existem grupos étnicos vivendo em alto nível de pobreza e degradação ambiental, sendo uma razão relevante para refletir sobre a necessidade de gestão ambiental participativa, de modo que esses povos não permaneçam marginalizados com suas crenças, valores e práticas, mas que sua organização social seja considerada no processo de gestão, especialmente por conta da relação afetiva que essa população estabelece com o ambiente natural. Todavia, a mudança nos modos de vida desses povos em função da economia moderna pode colocá-los em uma situação de vulnerabilidade, não apenas econômica, mas social e cultural afetando diretamente no modo como lidam com o seu meio. Em sua pesquisa, Caraton (2012), revela que os entrevistados admitem que a pesca artesanal pode causar impactos

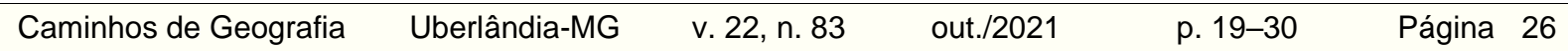


Pesquisas sobre percepção ambiental em comunidades tradicionais com abordagens sobre os motivos da valoração ambiental: uma incursão nas dissertações e teses de 2009 - 2017
Joscélia Monteiro Santos de Brito Emilly da Silva Farias Raquel Viana Quinelato Allison Gonçalves Silva

negativos ao meio ambiente quando, por exemplo, um peixe é fisgado e levado para consumo sem deixá-lo crescer o suficiente, podendo essa ação, ser indício de uma vulnerabilidade econômica provocada nos novos arranjos sociais da vida moderna. $O$ que evidencia que a identidade dos territórios se dá ao longo do tempo e espaço a partir da coletividade que nele vive.

A valoração simbólica está relacionada ao elo e ao pertencimento, sentimentos importantes para balizar o modo de agir das pessoas, enquanto a valoração econômica do meio ambiente tem condições de estimar os benefícios socioeconômicos promovidos, tanto para as comunidades tradicionais quanto para os que usufruem dos recursos provenientes delas (VIEIRA, 2014). Com isso, em termos de valoração ambiental, não há supremacia entre aspectos de valoração simbólica e econômica numa comunidade tradicional, uma vez que essas coexistem. Entretanto, os modos de perceber o ambiente não são imutáveis, pois os recursos naturais estão disponíveis em tempo e espaço diferentes, por isso beneficiam grupos sociais em diferentes locais, com interesses diversos, podendo, a valoração ambiental ser modificada dentro do mesmo espaço, através do tempo a partir das relações estabelecidas na comunidade (ORDONEZ, 2017).

Identificar a percepção das comunidades tradicionais quanto aos valores simbólicos e econômicos dos seus recursos naturais, pode propiciar acordos de condutas ambientalmente favoráveis, uma vez que, atitudes sustentáveis estão ligadas às experiências, interesses e valores dos indivíduos e/ou grupos sociais. Considerando o elo que esses povos estabelecem com suas terras, o conhecimento que possuem acerca do ambiente em que vivem, suas tradições e singularidades culturais, as políticas públicas ambientais propostas devem ser pensadas no intuito de proteger a identidade desses povos, especialmente no que se refere ao acesso e utilização de seus recursos naturais em seus territórios. De forma participativa, estabelecer políticas com regras consensuais sobre o uso dos recursos naturais, demarcação de terras e áreas a serem protegidas, sem necessariamente, retirar dessas comunidades sua cultura e seus modos de vida, por meio de medidas impostas pelo Estado. A gestão participativa traz benefícios quanto aos arranjos sociais nesses territórios, podendo evitar processos de gentrificação, especulação imobiliária, exploração do trabalho e migração dessas populações, portanto, além dos benefícios ambientais, podem ocorrer benefícios econômicos, sociais e culturais (MARTINEZ, 2011; NASCIMENTO, 2013).

\section{CONSIDERAÇÕES FINAIS}

O fato de comunidades tradicionais remeterem quase que instantaneamente a ideia de apego ao lugar, ao uso comum do território, intensa relação solidária e essência étnico cultural, não quer dizer que as percepções quanto aos valores ambientais estejam apenas relacionadas aos aspectos simbólicos. Nas pesquisas acadêmicas, aspectos econômicos se mostram importantes para essas comunidades, todavia, esses aspectos se mostram fortemente atrelados a subsistência desses povos, manutenção do seu legado cultural, histórico e social. Deste modo, os resultados sugerem que os estudos sobre a percepção ambiental em comunidades tradicionais relacionam-se a gestão ambiental numa proposta participativa. Para efetividade de estudos dessa natureza, no entanto, fazse necessário uma abordagem aprofundada sobre as peculiaridades do território e dos complexos arranjos da territorialidade dessas populações, para de fato acessar e compreender de forma clara as percepções e valores ambientais desses povos.

As populações tradicionais tendem a se relacionar com o ambiente natural de forma a valorar este meio como um bem de subsistência, promovendo o manejo dos recursos naturais sem visar o lucro direto, mas sim sua reprodução social e cultural, devido ao elo que estabelecem com o local em que vivem. Apesar disso, ao se depararem em situações de vulnerabilidade, esses povos podem manter atitudes ambientalmente prejudiciais que poderiam ser amenizadas a partir de intervenções de gestão ambiental adequadas, construídas a partir da territorialidade dessas populações, suas percepções e expectativas. Por isso, estudos acadêmicos sobre percepção com o propósito de criar quadros explicativos, poderiam auxiliar na promoção de ações de gestão ambiental coerentes com a realidade dessas comunidades.

\section{REFERÊNCIAS}

ANTONIO, D. G. Comunidades Sustentáveis: um estudo de percepção, interpretação e valoração da paisagem mediante o conhecimento tradicional. $262 \mathrm{f}$. Tese (Doutorado em geografia). Universidade

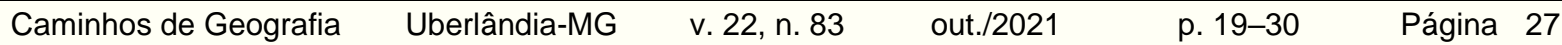


Pesquisas sobre percepção ambiental em comunidades tradicionais com abordagens sobre os motivos da valoração ambiental: uma incursão nas dissertações e teses de 2009 - 2017
Joscélia Monteiro Santos de Brito Emilly da Silva Farias Raquel Viana Quinelato Allison Gonçalves Silva

Estadual Paulista de Rio Claro, 2013. Disponível em:

$<$ https://repositorio.unesp.br/handle/11449/104440>. Acesso em: 18 jun. 2020.

BAPTISTA, C. P. B. O conhecimento ecológico local e a percepção ambiental de uma população de pescadores do Rio Grande do Sul. 93 f. Tese (Doutorado em biologia) - São Leopoldo: Universidade do Vale do Rio dos Sinos, 2011. Disponível em:

$<$ http://www.repositorio.jesuita.org.br/handle/UNISINOS/4549>. Acesso em: 18 jun. 2020.

BARBIERI, J. C; SILVA, D. da. Desenvolvimento sustentável e educação ambiental: uma trajetória comum com muitos desafios. Revista de Administração Mackenzie. Edição Especial, São Paulo, v. 12, n. 3, p. 51-82, 2011. Disponível em: <https://www.scielo.br/scielo.php?pid=S1678-

$69712011000300004 \&$ script=sci abstract\&tlng=pt>. Acesso em: 18 jun. 2020. https://doi.org/10.1590/S1678-69712011000300004

CAILLÉ, A. O princípio de razão, o utilitarismo e o antiutilitarismo. Sociedade e Estado, Brasília, v. 16, n. 1-2, p. 26-56, 2001. Disponível em: <

https://www.scielo.br/scielo.php?script=sci arttext\&pid=S0102-69922001000100003 >. Acesso em: 18 jun. 2020. https://doi.org/10.1590/S0102-69922001000100003

CARANTON, M. A. G. Pagamentos pelos serviços ambientais no ecossistema manguezal das unidades de conservação de Sabiaguaba: modelo de contrato e outras medidas de conservação. 111 f. Dissertação (Mestrado em desenvolvimento e meio ambiente) - Fortaleza: Universidade Federal do Ceará, 2012. Disponível em: < http://www.repositorio.ufc.br/handle/riufc/14125>. Acesso em: 18 jun. 2020.

CISOTTO, M. F. Sobre topofilia, de Yi-fu Tuan. Geograficidade, v.3, n.2, Inverno 2013. Disponível em: <https://periodicos.uff.br/geograficidade/article/view/12868>. Acesso em: 18 jun. 2020. https://doi.org/10.22409/geograficidade2013.32.a12868

DIEGUES, A. C. S. 0 mito moderno da natureza intocada. 4ª ed. São Paulo: Hucitec, USP, 2004.

Biodiversidade e Comunidades Tradicionais no Brasil. São Paulo: NUPAUBUSP, PROBIO-MMA, CNPq, 2000.

FERNANDES, J. Percepção ambiental: as transformações no cotidiano de caiçaras de Ubatuba-SP na década de 1960 e na primeira década do século XXI. 137 f. Dissertação (Mestrado em Ciências Ambientais) - Taubaté: Universidade de Taubaté, 2009. Disponível em:

$<$ http://www.bdtd.unitau.br/tedesimplificado/tde arquivos/1/TDE-2012-08-29T095931Z-

162/Publico/Joice\%20Fernandes.pdf>. Acesso em: 18 jun. 2020.

FERREIRA, M. S. F. D. Lugar, recursos e saberes dos ribeirinhos do médio rio cuiabá, Mato Grosso. 180 f. Tese (Doutorado ciências biológicas) - São Carlos: Universidade Federal de São Carlos, 2010. Disponível em: <https://repositorio.ufscar.br/handle/ufscar/1694?show=fulll $>$. Acesso em: 18 jun. 2020.

FREIRE, A. L. B. F. Etnobotânica e percepção ambiental de pescadores e coletoras tradicionais submetidos à escassez de recursos vegetais silvestres. $86 \mathrm{f}$. Dissertação (Mestrado em desenvolvimento e meio ambiente) - Natal: Universidade Federal do Rio Grande do Norte, 2015. Disponível em: $<\underline{h}$ https://repositorio.ufrn.br/jspui/handle/123456789/21090>. Acesso em: 18 jun. 2020.

JACOBI, P. Participação. In: BRASIL. Encontros e caminhos: formação de educadoras (es) ambientais e coletivos educadores. Brasília - DF: Ministério do Meio Ambiente, p. 231-236, 2007.

LACERDA, R. dos S. Territorialidade, saúde e meio ambiente: conexões, saberes e práticas em comunidades quilombolas de Sergipe. $249 \mathrm{f}$. Tese (Doutorado em desenvolvimento e meio Ambiente) - São Cristovão: Universidade Federal de Sergipe, 2017. Disponível em: $<$ http://bdtd.ibict.br/vufind/Record/UFS-2 877fcb793d3f3c2bcf395ed3f403f7d8 >. Acesso em: 18 jun. 2020.

MARTINEZ, D. I. Representações e percepções sobre ambiente e conservação como subsídio ao Gerenciamento Costeiro Integrado: estudo de caso com grupos sociais da região de Cananéia, litoral sul do Estado de São Paulo. 183f. Dissertação (Mestrado em Ciências) - São Paulo: Universidade de São Paulo, 2012. Disponível em: <https://www.teses.usp.br/teses/disponiveis/21/21134/tde11122012-160745/pt-br.php > Acesso em: 18 jun. 2020. 
Pesquisas sobre percepção ambiental em comunidades tradicionais com abordagens sobre os motivos da valoração ambiental: uma incursão nas dissertações e teses de 2009 - 2017
Joscélia Monteiro Santos de Brito Emilly da Silva Farias Raquel Viana Quinelato Allison Gonçalves Silva

MATTOS, P. P. Entendendo as interações entre povos pesqueiros, manguezal e área protegida: RDS estadual ponta do tubarão. 105 f. Dissertação (Mestrado em desenvolvimento e meio ambiente) Natal: Universidade Federal do Rio Grande do Norte, 2011. Disponível em: $<$ http://repositorio.ufrn.br:8080/jspui/handle/123456789/18215>. Acesso em: 18 jun. 2020.

MENDES, K. D. S.; SILVEIRA, R. C. de C. P.; GALVÃO, C. M. Revisão integrativa: método de pesquisa para a incorporação de evidências na saúde e na enfermagem. Texto \& contexto enfermagem, v. 17, n. 4, p. 758-764, 2008. Disponível em:

$<$ https://www.scielo.br/scielo.php?pid=s0104-07072008000400018\&script=sci arttext >. Acesso em: 18 jun. 2020. https://doi.org/10.1590/S0104-07072008000400018

MENDONÇA, M. das G.; COLESANTI, M. T. de M. Reflexões sobre teoria e prática em educação ambiental: estudo de caso da percepção ambiental da população do município de Uberlândia (MG). Caminhos de Geografia, Uberlândia, v. 16, n. 56, 2015. Disponível em:

<http://www.seer.ufu.br/index.php/caminhosdegeografia/article/view/30493>. Acesso em: 18 jun. 2020

MONTEIRO, G. R. F. F.; ALMEIDA, A. L. T. A. Território e territorialidades dos povos e "comunidades tradicionais" no brasil: uma aproximação. Revista Interdisciplinar em Educação e Territorialidade, v. 1, n. 1, 2020. Disponível em: <https://ojs.ufgd.edu.br/index.php/riet/article/view/12968>. Acesso em: 28 jul 2021. https://doi.org/10.30612/riet.v1i1.12968

NASCIMENTO, P. S. S. do. Gestão em áreas protegidas: proposição metodológica para análise de impactos socioambientais nas comunidades tradicionais da APA Chapada do Araripe. 205 f. Tese (Doutorado em Geografia) - Rio Claro: Universidade Estadual Paulista Júlio de Mesquita Filho, 2013. Disponível em: <http://bdtd.ibict.br/vufind/Record/UNSP 2ce70f2269e78d436fea415bfa64b292>. Acesso em: 18 jun. 2020.

ORDONEZ, L. V. L. Serviços ecossistêmicos e interações com uma comunidade afrodescendente no pacífico colombiano: dos riscos à proteção da biodiversidade. $141 \mathrm{f}$. Dissertação (Mestrado em desenvolvimento e meio ambiente) - João Pessoa: Universidade Federal da Paraíba, 2017.

Disponível em: < https://repositorio.ufpb.br/ispui/bitstream/tede/9047/2/arquivototal.pdf Acesso em: 18 jun. 2020.

PIMENTEL, R. L. Estrutura florística e implicações socioambientais na área de preservação permanente Tarumã Mirim, Manaus - AM. 100 f. Dissertação (Mestrado em ciências florestais e ambientais) - Manaus: Universidade Federal do Amazonas, 2016. Disponível em: $<$ https://tede.ufam.edu.br/handle/tede/5340>. Acesso em: 18 jun. 2020

RAYEL, R. S. Paisagens Turísticas: conexões ambientais e educacionais. Caderno de Geografia, v. 26, n.47, 2016. Disponível em: <http://periodicos.pucminas.br/index.php/geografia/article/view/p.23182962.2016v26n47p629Acesso em: 18 jun. 2020. https://doi.org/10.5752/p.2318$\underline{2962.2016 \mathrm{v} 26 \mathrm{n} 47 \mathrm{p} 629}$

RICKLEFS, R.; RELYEA, R.. A Economia da Natureza. 7 ed. Rio de Janeiro: Guarnabara Koogan, 2010.

ROSA, M. V. de F. P.; ARNOLDI, M. A. G. C. A entrevista na pesquisa qualitativa: mecanismo para validação dos resultados. Belo Horizonte: Autêntica, 2008.

SORRENTINO, M.; TRAJBER, R.; MENDONÇA, P.; JUNIOR, L. A. F. Educação ambiental como política pública. Educação e Pesquisa, São Paulo, v. 31, n. 2, p. 285-299, 2005. Disponível em: $<$ https://www.scielo.br/pdf/ep/v31n2/a10v31n2.pdf >. Acesso em: 18 jun. 2020. https://doi.org/10.1590/S1517-97022005000200010

SUESS, R. C.; BEZERRA, R. G.; SOBRINHO, H. de C. Percepção ambiental de diferentes atores sociais sobre o Lago do Abreu em Formosa - GO. HOLOS, Rio Grande do Norte, v. 6, p. 241-258, 2013. Disponível em: <http://www2.ifrn.edu.br/ojs/index.php/HOLOS/article/view/1287>. Acesso em: 18 jun. 2020. https://doi.org/10.15628/holos.2013.1287

TUAN, Yi-Fu. Topofilia: Um estudo da percepção, atitudes e valores do meio ambiente. Tradução de: Lívia de Oliveira. Londrina: Eduel, 2015.

UNESCO. Rapport final du groupe d'experts sur le project 13: La perception de la quilité du milieu de Programme sur l'homme et la biosphére (MAB). Paris: UNESCO, 1973. 
VIEIRA, F. S. Economia do conhecimento tradicional e a valoração econômica como instrumento de sua conservação: o caso das mandiocas açucaradas. 85 f. Dissertação (Mestre em Economia Gestão Econômica do Meio Ambiente) - Brasília: Universidade de Brasília, 2014. Disponível em: $<$ https://repositorio.unb.br/handle/10482/18999>. Acesso em: 18 jun. 2020.

Recebido em: 24/06/2020

Aceito para publicação em: 01/09/2021 